Ашурбеков Н.А., Шахсинов Г.Ш., Исрапов Э.Х., Исаева З.М. Взаимодействие низкотемпературной плазменной струи атмосферного давления в смеси воздуха и аргона с биотканями

УДК 537.523

DOI: $10.21779 / 2542-0321-2019-34-2-19-35$

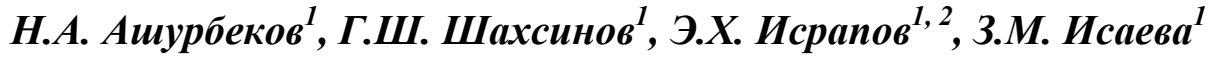

\section{Взаимодействие низкотемпературной плазменной струи атмосферного давления в смеси воздуха и аргона с биотканями}

\author{
ФГБОУ ВО «Дагестанский государственный университет», Россия, \\ 2. Махачкала, 367001, ул. М. Гаджиева, 43 a; nashurb@mail.ru; \\ ${ }^{2}$ Институт физики им. Х.И. Амирханова Дагестанского научного иентра Рос- \\ сийской академии наук; Россия, 367003, Махачкала, ул. Ярагского, 94; еd- \\ gar1993@yandex.ru
}

Разработана и исследована газоразрядная система для формирования низкотемпературной плазменной струи в смеси воздуха с аргоном для биомедицинских приложений. Описана конструкция плазменного источника и приведены экспериментальные результаты исследования пространственной структуры плазменной струи, спектрального состава излучения и температуры на различных участках плазменной струи. Выполнены предварительные микрофлуоресцентные исследования воздействия низкотемпературной плазменной струи на образцах биоткани печени in vitro. разряд.

Ключевые слова: плазменная медииина, плазменная струя, наносекундный барьерный

За последние 50-60 лет газоразрядная плазма стала частью мощной индустрии, включающей в себя такие промышленные разработки, как плазменные и газовые лазеры, мощные газоразрядные источники УФ излучения, электродуговая сварка, плазменная резка, нанесение защитных покрытий, травление подложек для создания микросхем, плазменные экраны и др. Начиная с последних 10-20 лет плазму активно стали применять в биологических и медицинских исследованиях. Были положены основы нового междисциплинарного прикладного научного направления, которое получило название «плазменная медицина». В исследованиях в этой области принимают участие не только специалисты в области физики плазмы, но и биологи, химики, медики. В настоящее время частично исследованы различные аспекты плазменной медицины как междисциплинарной отрасли между химией плазмы и медициной. В частности, показано, что сложные биологические процессы в живых системах можно контролировать, стимулировать, катализировать и диагностировать с использованием низкотемпературной воздушной плазмы атмосферного давления. Во многих работах экспериментальным путем было обнаружено, что плазма газового разряда может давать целенаправленный неразрушающий терапевтический эффект при стерилизации, быстром свертывании крови, заживлении ран, а также при лечении некоторых кожных заболеваний [1-11].

Однако практически все исследования, выполненные к настоящему времени в данном направлении, носят качественный характер и не содержат детального анализа физических и химико-биологических процессов взаимодействия плазмы с живыми системами. Дальнейшее развитие и внедрение этой передовой технологии в медицине требует детального понимания очень сложных физико-химических и биологических 
Ашурбеков Н.А., Шахсинов Г.Ш., Исрапов Э.Х., Исаева 3.М. Взаимодействие низкотемпературной плазменной струи атмосферного давления в смеси воздуха и аргона с биотканями

механизмов комплексного взаимодействия плазмы с биотканями, клетками, микроорганизмами и другими биологическими системами.

В настоящей работе сообщается о результатах исследования воздействия низкотемпературной плазменной струи атмосферного давления в смеси воздуха и аргона на спектры флуоресценции биотканей.

\section{1. Актуальность исследования}

Анализ и обобщение большого числа публикаций различных научных групп в области плазменной медицины [1-22] показывает, что по характеру воздействия плазмы на биологические объекты и ожидаемому результату можно выделить три большие подгруппы в современной плазменной медицине:

- непосредственное терапевтическое воздействие плазмы на биологический объект;

- стерилизация и обеззараживание медицинского оборудования;

- модификация поверхности медицинских инструментов и имплантов.

Одним из способов получения плазменной струи в смеси инертных газов и воздуха является наносекундный барьерный разряд. При этом используются импульсы с амплитудой несколько киловольт, длительностью от наносекунд до микросекунд, и частотой повторения от 100 Гц до 10 кГц. Газовая температура плазменного факела при этом находится в пределах $300-500 \mathrm{~K}$, а длина плазменного образования на выходе генератора может достигать $11 \mathrm{~cm}$. При использовании в качестве буферного газа $\mathrm{He}, \mathrm{Ar}$ или $\mathrm{N}_{2}$ исследователями зафиксированы [1] уничтожение бактерий различных видов и коагуляция крови.

Физические механизмы взаимодействия плазмы с живыми тканями и клетками имеют сложную природу как из-за состава и механизмов элементарных процессов в плазме, так и из-за структуры биоткани и клеток, представляющих из себя многокомпонентную среду из многоатомных и биополимерных молекул. Таким образом, объединение всех механизмов взаимодействия плазмы с живой системой и построение единой теории плазменной медицины может оказаться невозможным.

В настоящее время в ряде работ представлен анализ взаимодействия различных типов разрядов, в частности диэлектрического барьерного разряда, с живыми тканями и клетками и обсуждаются различные биологические и физические механизмы воздействия плазмы на биоткань. В обсуждаемых в настоящее время физических механизмах заряженные частицы плазмы идентифицируются как основные факторы, способствующие желаемому эффекту, и предлагается механизм такого взаимодействия. Кроме того, рассматриваются биологические механизмы и выдвигается гипотеза селективности воздействия плазмы и ее эффектов в зависимости от сорта заряженных частиц. Применение неравновесных плазменных источников к биотканям показало, что плазма избирательно реагирует на патогены, стерилизацию и стимулирование сложных биологических реакций с минимальным повреждением обработанных тканей и клеток или без него. На основании экспериментальных данных с тканью человека, живыми мышами, живыми свиньями и клетками различных млекопитающих (макрофаги, эпителиальные клетки, b-лимфоциты, фибробласты и раковые клетки меланомы) были выдвинуты три основные гипотезы по механизмам селективного воздействия плазмы на живую системy:

1. Метаболизмы клеток бактерий и клеток млекопитающих различаются между собой. 
Ащурбеков Н.А., Шахсинов Г.Ш., Исрапов Э.Х., Исаева З.М. Взаимодействие низкотемпературной плазменной струи атмосферного давления в смеси воздуха и аргона с биотканями

2. Организмы более высокого порядка развили больше механизмов сопротивления внешнему воздействию.

3. Бактериальные клетки, как правило, намного меньше, чем клетки млекопитающих, и поэтому для инактивации того же количества бактерий требуется более низкая доза внешнего воздействия по сравнению с клетками млекопитающих.

Эти гипотезы, конечно, являются вполне феноменологическими, и требуется дальнейшее детальное тестирование, чтобы получить правильное описание. Однако ряд авторов приводит доказательства в пользу этих идей [3-9]. Этими авторами был представлен анализ взаимодействия диэлектрического барьерного разряда с живыми тканями и клетками и его биологических и физических механизмов. Заряженные частицы в физических механизмах были идентифицированы как основные факторы, способствующие желаемому эффекту. Был предложен механизм этого взаимодействия на основе существующих в радиобиологии механизмов. Аналогичные механизмы были предложены для плазмы высокочастотного диэлектрического барьерного разряда (ВЧБР). Кроме того, было продемонстрировано, что плазма ВЧБР оказывает биологическое воздействие на биоткани и клетки, и ее терапевтический эффект потенциально может стать значимым с медицинской точки зрения. Это может быть использовано в лечении таких заболеваний, как рак кожи. Было показано, что плазменная обработка избирательно взаимодействует с некоторыми компонентами крови для стимулирования свертывания крови путем инициации или катализа биохимических процессов, ранее существовавших в крови. Следует отметить, что «подача» реакционноспособных агентов плазмы происходит на газообразном уровне, а это означает, что нет необходимости в носителе и доступ к обрабатываемой поверхности является оптимальным.

Хотя эти результаты потенциально перспективны, остается много нерешенных вопросов и пробелов в понимании механизмов воздействия плазмы на живую систему. Селективность также остается открытым вопросом. Необходимо более глубокое исследование как избирательности, так и механизма взаимодействия плазмы с бактериальными и паразитарными клетками. Селективность очевидна, но ее механизмы до конца не раскрыты, хотя авторы представили ряд потенциальных гипотез [12-15].

Доставка медикоактивных «веществ» на молекулярном или ионном уровне - еще одно возможное направление исследований через воздействие на клеточные стенки, возбуждение клеток и введение реактивных воздействий в клеточную цитоплазму. Электрические поля, зарядка поверхностей, потоки тока и т. д. также могут влиять на ткань, приводя к повышенной проницаемости клеточных стенок для доставки лекарств [14].

Анализ широкого круга периодической научной литературы в области плазменной медицины показывает, например [1-22], что можно выделить следующие основные физические факторы воздействия низкотемпературной плазмы на биологические среды и биоматериалы:

- электромагнитные поля и УФ излучение;

- заряженные частицы - электроны и ионы;

- кислородосодержащие радикалы (ROS: O, $\mathrm{O}_{2-}, \mathrm{O}_{3}, \mathrm{H}_{2} \mathrm{O}_{2}$ ). Влияние на метаболизм клеток, клеточные мембраны, окисление липидов, протеинов, ДНК;

- азотосодержащие радикалы (RNS: $\mathrm{N}, \mathrm{NO}, \mathrm{NO}_{2}, \mathrm{NO}_{3}, \mathrm{~N}_{2} \mathrm{O}_{5}$ ). Влияние на клетки, клеточная сигнализация.

В основном роль ионов сводится к катализу окислительных процессов в присутствии кислородосодержащих радикалов. УФ излучение оказывает непосредственное 
Ашурбеков Н.А., Шахсинов Г.Ш., Исрапов Э.Х., Исаева З.М. Взаимодействие низкотемпературной плазменной струи атмосферного давления в смеси воздуха и аргона с биотканями

антибактерицидное воздействие. Положительные и отрицательные ионы, УФ излучение, нейтральные атомы плазмы оказывают воздействие на биологический объект различными способами, в комплексе вызывая синергетический эффект. Более того, воздействие ионов, как было отмечено выше, может иметь и селективный характер. Например, авторами [22] подробно описаны химические процессы с участием кислородосодержащих радикалов. Приведены химические реакции на различных участках плазменного факела при взаимодействии его с биологической тканью, а также модель взаимодействия плазма-биопленка и плазма-биоткань.

\section{2. Экспериментальная установка для получения низкотемпературной плазмы в струе газа атмосферного давления}

Имеющиеся в литературе данные показывают, что для использования в медицинских целях необходимо иметь низкотемпературную плазму, в которой формировались бы кислород- и азотсодержащие радикалы, ионы, УФ излучение и достаточно высокие электрические поля. Для создания такой плазменной струи нами был использован барьерный разряд в цилиндрическом плазменном волноводе, через разрядный промежуток которого пропускается аргон в присутствии воздуха атмосферного давления. В зависимости от скорости прокачки инертного газа можно регулировать процентное содержание аргона в воздухе, а также соотношение радикалов, содержащих кислород и азот как составные компоненты воздуха.

Схема использованного в данной работе разрядного устройства для получения плазменной струи представлена на рис. 1 [23-25]. Была использована кварцевая разрядная трубка внешним диаметром 7 мм и внутренним 1 мм. Один из электродов представлял собою металлический стержень диаметром 0,5 мм, находящийся внутри кварцевой трубки, на расстоянии 60 мм от него снаружи кварцевой трубки установлен второй электрод, представляющий собой заземленное металлическое кольцо шириной 5 мм, диаметр которого совпадает с внешним диаметром кварцевой трубки. Установка позволяла менять расстояние между электродами в пределах от 3 до 7 см. В зависимости от этого расстояния регулировался ток разряда и геометрические размеры ионизованной области. Через такую систему пропускался инертный газ (аргон), который, смешиваясь с воздухом, формировал смесь воздуха и инертного газа, в котором возникал барьерный разряд по внутренней поверхности трубки. Для формирования барьерного газового разряда использовался высоковольтный импульсный генератор трансформаторного типа, который формировал положительные импульсы напряжения амплитудой до 20 кВ, длительностью фронта импульса напряжения около 100 нс. 
Ашурбеков Н.А., Шахсинов Г.Ш., Исрапов Э.Х., Исаева З.М. Взаимодействие низкотемпературной плазменной струи атмосферного давления в смеси воздуха и аргона с биотканями

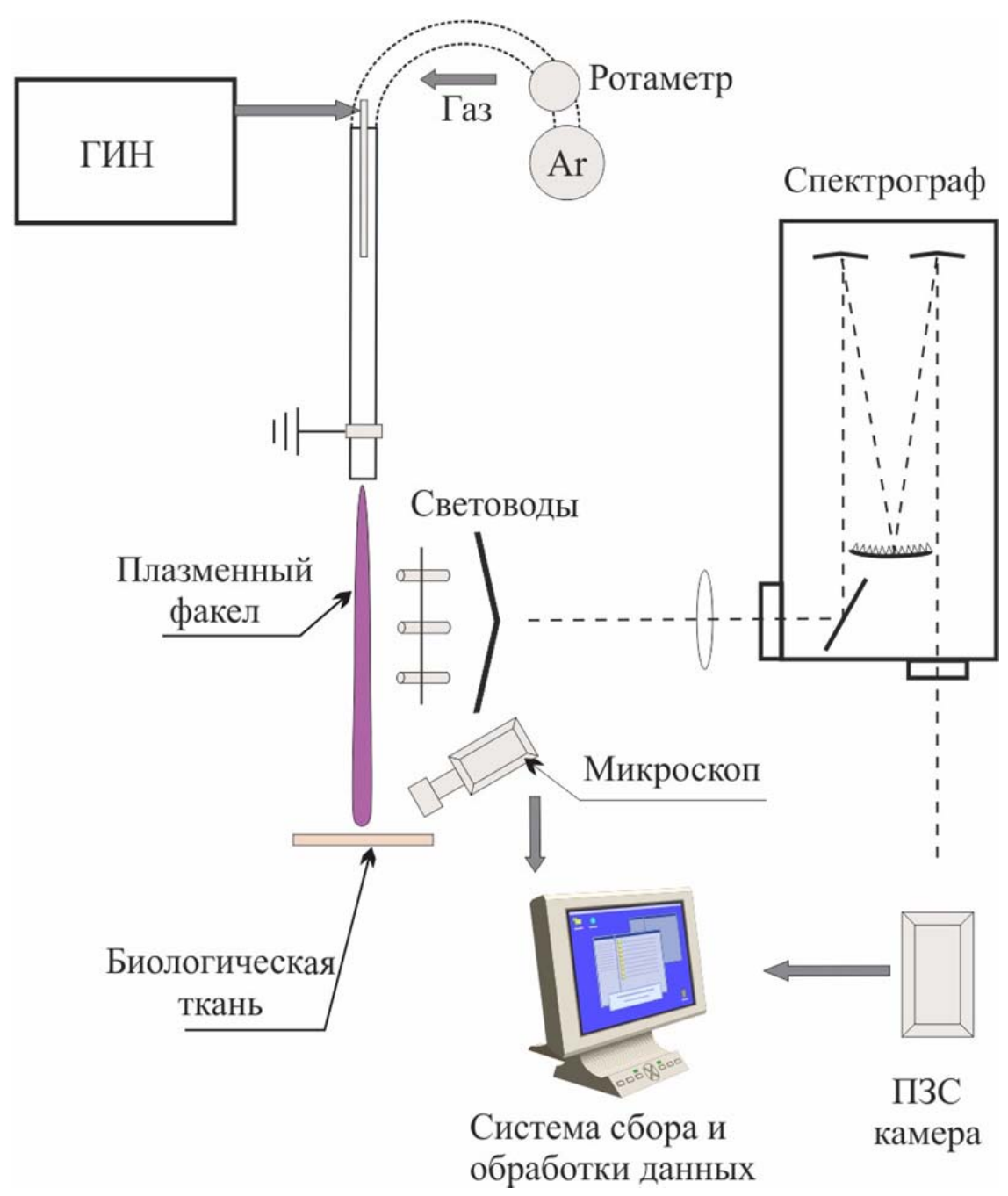

Рис. 1. Схема получения плазменного факела при атмосферном давлении в смеси воздуха и инертного газа

На разрядную трубку импульсы напряжения подавались с частотой повторения 100 Гц, что обеспечивало стабильность разряда вследствие предыонизации разрядного промежутка остаточным зарядом от предыдущих импульсов напряжения.

Использование наносекундного разряда позволяло обеспечить формирование интенсивного УФ излучения разряда и эффективную ионизацию газа, сохраняя при этом практически комнатную температуру газа, что является обязательным требованием к плазменным источникам для применения в медицинских целях.

Скорость потока газа через разрядную трубку контролировалась ротаметром с вентилем (РМ-А-0.063 ГУЗ). Изменением скорости потока газа контролировались физико-химические параметры плазменной факела (длина, газовая температура, спектральный состав излучения, химический состав).

Оптическое излучение плазменного факела через диафрагму с помощью кварцевых световодов и объектива проецировалось на входе спектрографа MS3504і (Беларусь). ПЗС камера $H S 103 H$, смонтированная на одном из выходных портов спектрографа, позволяла фиксировать панорамный спектр излучения плазменного факела. 
Перпендикулярно течению плазменной струи был установлен столик, позволяющий регулировать расстояние между выходом разрядной трубки и образцом биологической ткани, установленным на нем. Состояние образца до и после взаимодействия с потоком плазмы изучалось с помощью оптического микроскопа Nikon Eclipse Ni-U. Образцы биологических тканей толщиной 15 мкм подготавливались с помощью криостатного микротома CM-1510S (Leica Microsystem, Германия) и устанавливались на предметном стекле. Таким образом удавалось исследовать взаимодействие плазмы с различными образцами биологических тканей.

\section{3. Плазменная струя на основе барьерного разряда наносекундной длительности в смеси аргона и воздуха атмосферного давления}

На экспериментальной установке был получен плазменный факел в смеси аргона с воздухом атмосферного давления. Для этого через плазменный волновод, схематически изображенный на рис. 1, 2, пропускался спектрально чистый аргон в режиме потока газа, скорость которого регулировалась калиброванным ротаметром.

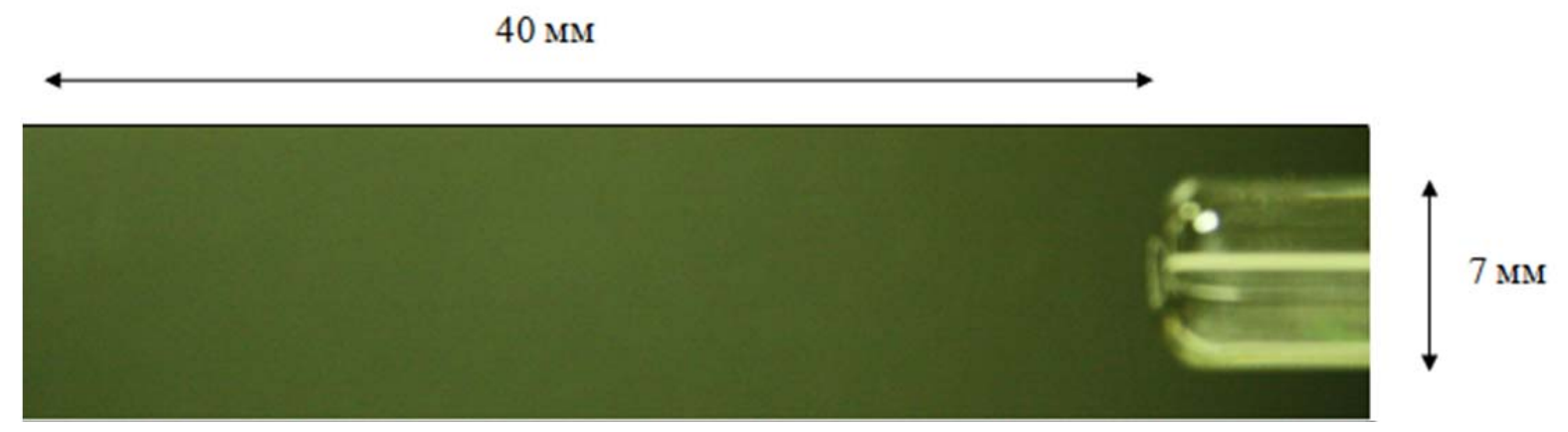

Рис. 2. Фотография выходного узла генератора плазмы

На рис. 3, 4 представлено распределение оптического излучения плазмы в поперечном и продольном сечении плазменного факела, полученное в режиме формирования барьерного разряда импульсами высокого напряжения амплитудой 14 кВ. Генератор высоковольтных импульсов напряжения позволял регулировать амплитуду импульсов напряжения ступенчато с промежуточными значениями от 14-20 кВ. Кроме того, регулировалась скорость истечения гелия в газовом потоке.

На фотографиях видна явная зависимость длины плазменного факела от скорости потока газа через разрядную трубку при фиксированном значении напряжения на электродах. Причем максимум длины соответствует скорости потока 0,32 л/мин. Так же условно плазменный факел визуально можно разделить на три ярко выраженные области, область яркого свечения (от 2 до 5 мм), область средней яркости и область на кончике факела, которые расплываются вследствие диффузии заряженных частиц.

В настоящей работе ток разряда имел емкостной характер вследствие того, что заземленный электрод непосредственно не соприкасался с плазмой, а был изолирован от потока газа стеклянной трубкой толщиной стенок 3 мм. Такая конфигурация позволяла задавать ток разряда шириной второго кольцевого электрода. 
Ашурбеков Н.А., Шахсинов Г.Ш., Исрапов Э.Х., Исаева З.М. Взаимодействие низкотемпературной плазменной струи атмосферного давления в смеси воздуха и аргона с биотканями

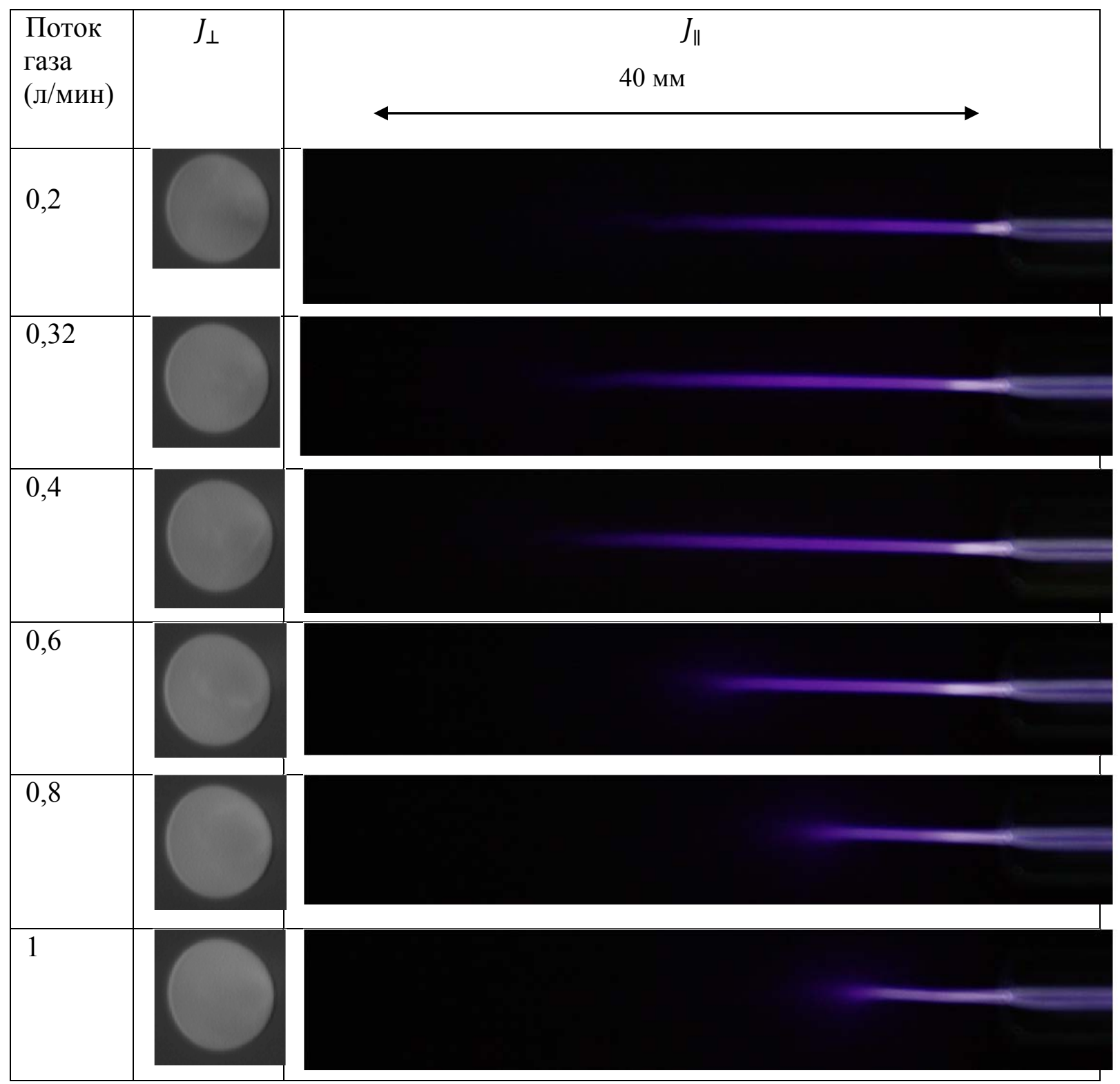

Рис. 3. Поперечное $J_{\perp}$ и продольное $J_{\|}$распределение интенсивности плазменного факела в зависимости от потока аргона сквозь разрядную трубку.

Для определения химического состава плазмы в факеле был исследован спектральный состав излучения с различных областей плазменного факела. В частности, на расстоянии 2, 10 и 15 мм от выхода разрядной трубки (рис. 5, 6). Полученные данные хорошо согласуются с фотографиями плазменного факела. Так, на фотографиях отчетливо выделяются как минимум три области интенсивности свечения, причем при отдалении от выходного торца разрядной трубки визуально виден переход свечения в более коротковолновую область. На спектрах снятых в трех различных участках, видно, что при отдалении от выходного торца разрядной трубки линии видимой спектральной области излучения уменьшают свою интенсивность до 6 раз, в то время как интенсивность линий УФ диапазона сначала вырастает в два раза, а далее уменьшается. 
Ашурбеков Н.А., Шахсинов Г.Ш., Исрапов Э.Х., Исаева З.М. Взаимодействие низкотемпературной плазменной струи атмосферного давления в смеси воздуха и аргона с биотканями
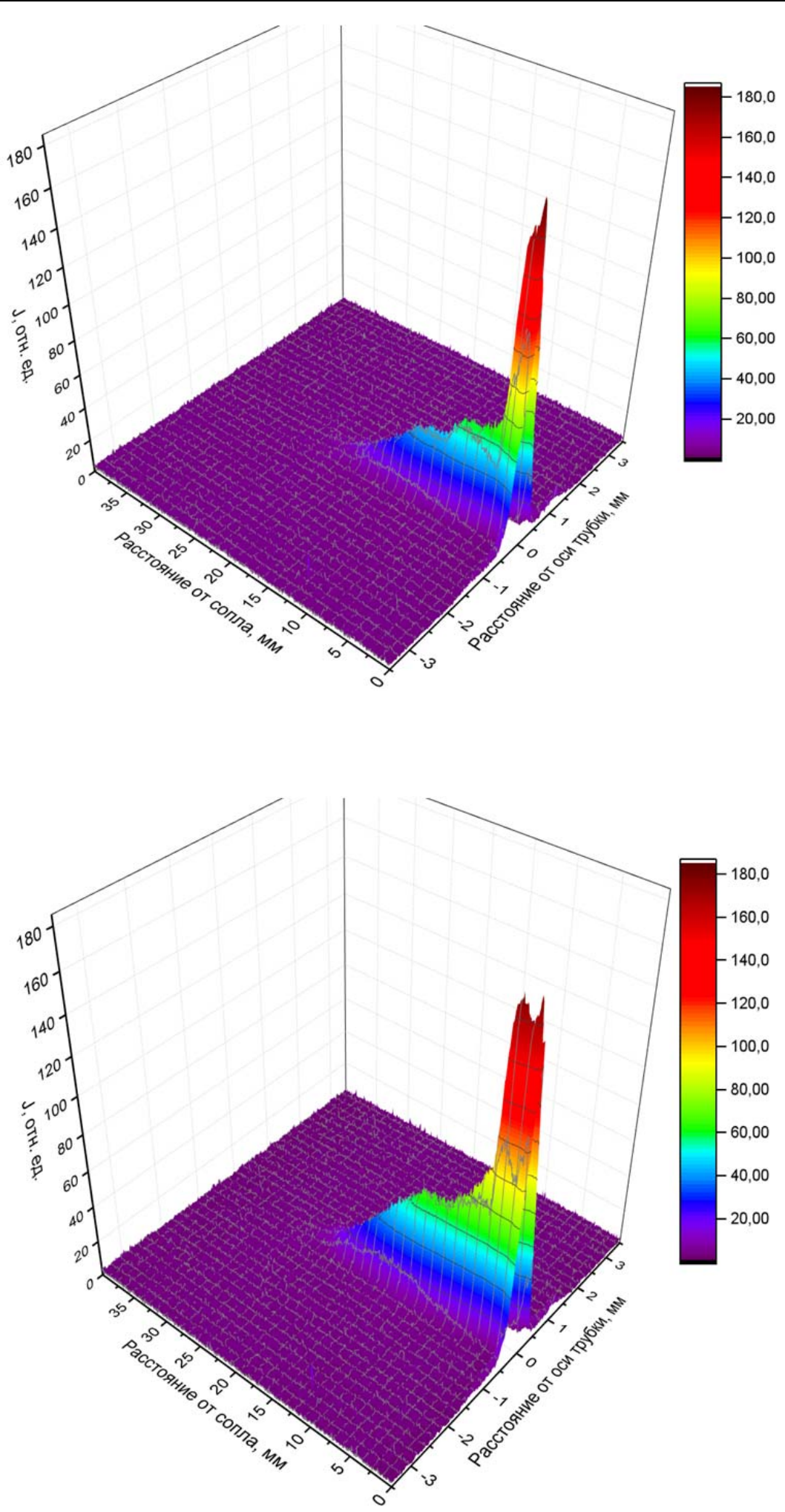

a 
Ашурбеков Н.А., Шахсинов Г.Ш., Исрапов Э.Х., Исаева З.М. Взаимодействие низкотемпературной плазменной струи атмосферного давления в смеси воздуха и аргона с биотканями
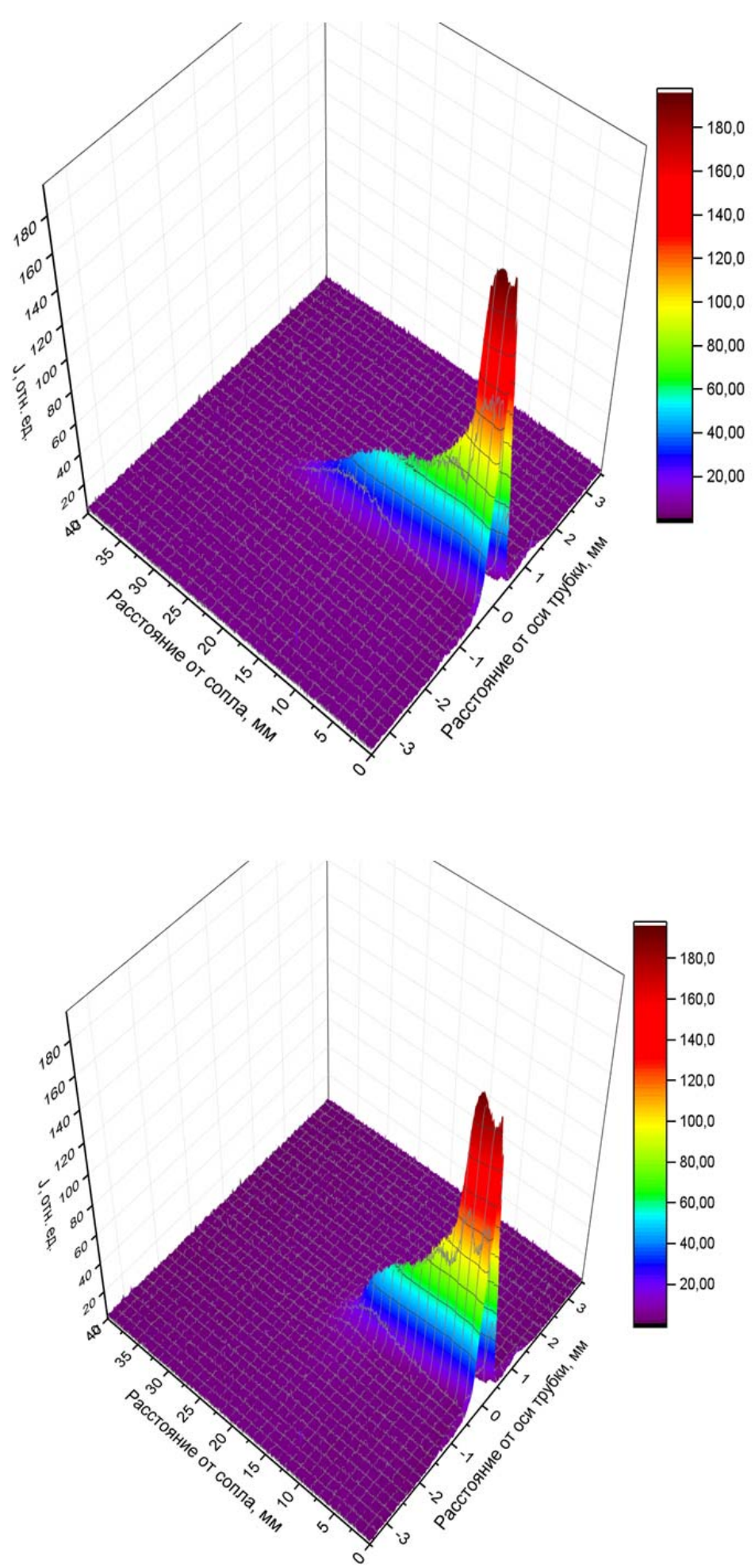

B 
Ащурбеков Н.А., Шахсинов Г.Ш., Исрапов Э.Х., Исаева З.М. Взаимодействие низкотемпературной плазменной струи атмосферного давления в смеси воздуха и аргона с биотканями
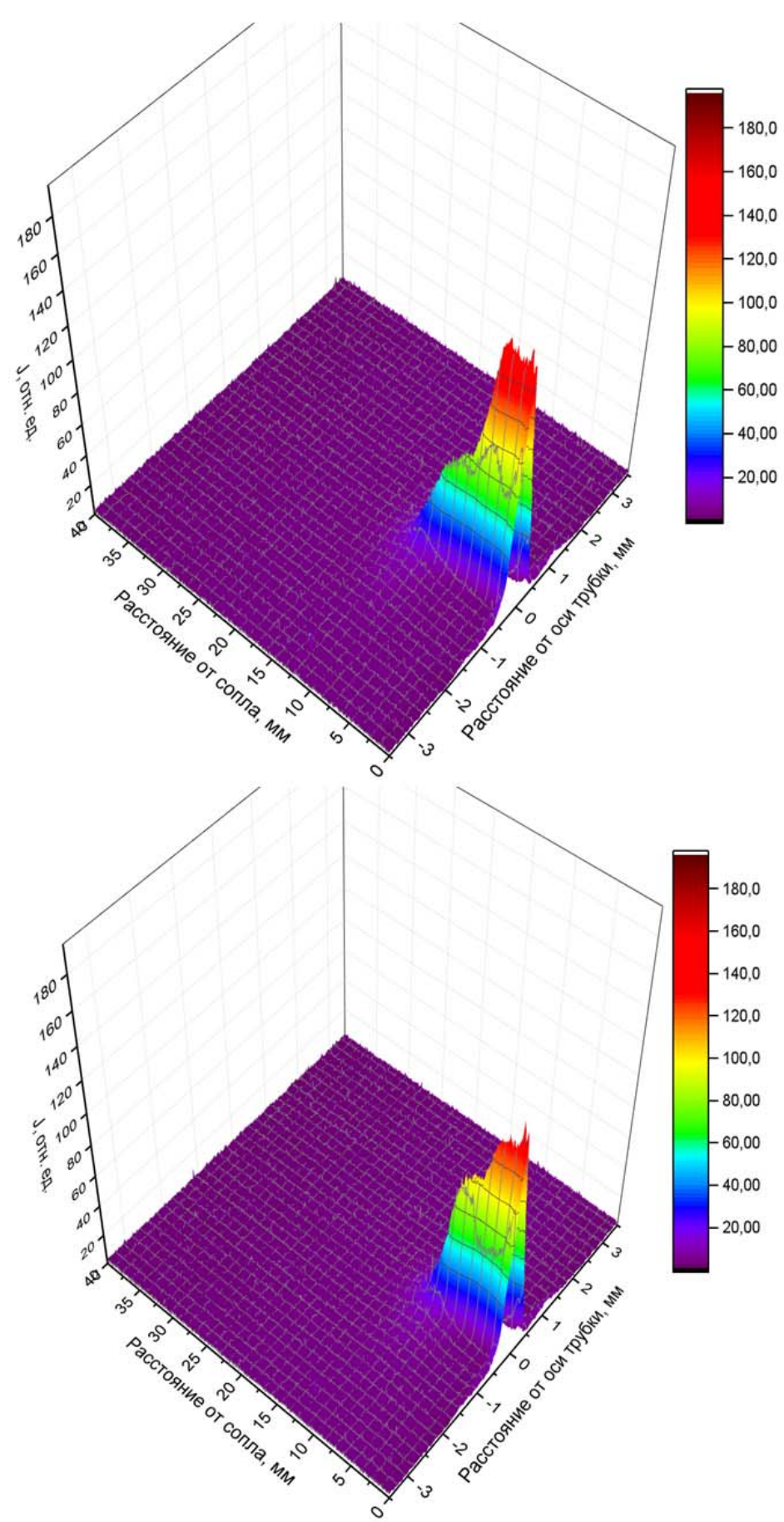

Д

e

Рис. 4. Распределение интенсивности свечения плазменного факела в зависимости от расхода аргона $(\mathrm{a}-0,2,6-0,32$, в $-0,4, \Gamma-0,6$, д - 0,8, e - 1 л/мин)

Так как плазменный факел распространяется по аргоновому каналу и смешивается с воздухом, в котором присутствует множество различных компонент, таких, как азот, кислород и т. д., очень важно знать спектральный состав излучения факела. На рисунке 6 показаны спектральные линии, которые идентифицированы с помощью баз NIST. Анализ показывает, что преимущественно в спектре присутствуют линии аргона и азота, а также гидроксильная группа. Наиболее заметные группы линий $\mathrm{N}_{2}(337$ нм, и 
др.), $\operatorname{Ar}\left(763,5\right.$ нм и др.), $\mathrm{OH}^{-}$(309 нм). Присутствие линии 309 нм показывает наличии водяного пара в газовой среде, в результате диссоциации молекул воды образуются радикалы $\mathrm{OH}^{-}$. Линия излучения при 309 нм - это линия возбужденного гидроксильного радикала [26-27].

Важной особенностью плазменного факела является то, что газовая температура может быть сравнима с комнатной. Это делает безопасным медицинское применение подобных технологий и предотвращает коагуляцию биологических тканей и последующее их омертвение. Измерения показали, что вдоль плазменного факела газовая температура меняется незначительно и остается в пределах $32-33{ }^{\circ} \mathrm{C}$ (рис. 7). Измерения проводились с использованием термометра ТТЖ-М с точностью $0,5{ }^{\circ} \mathrm{C}$. Для этого рабочая часть термометра погружалась в поток плазменной струи и выдерживалось достаточное время для установления теплового равновесия.

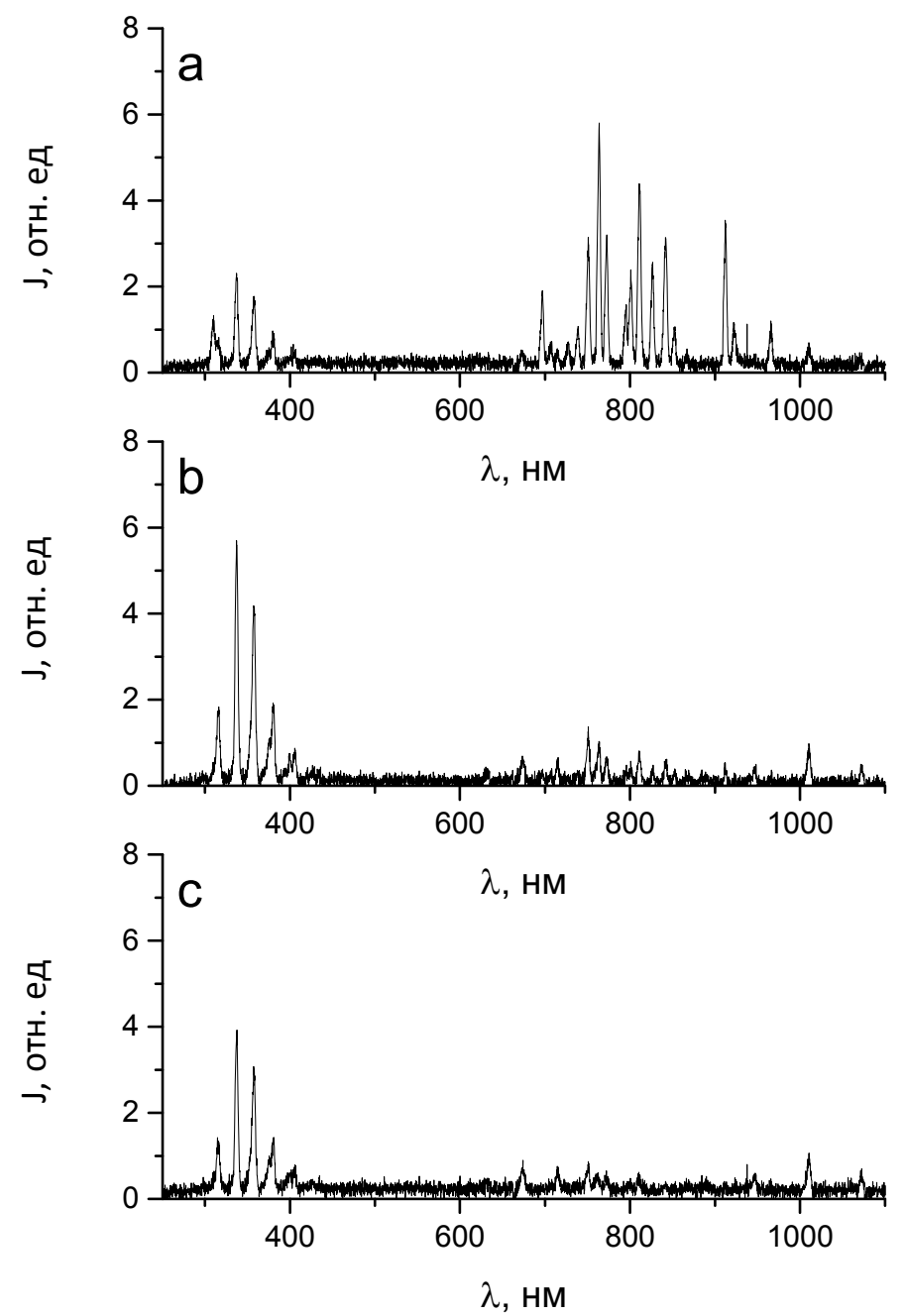

Рис. 5. Спектральное распределение интенсивности излучения, снятое поперек движения факела на различных расстояниях от сопла ( $a-2$ мм, $b-10$ мм, $c-15$ мм). Поток аргона 0,32 л/мин 


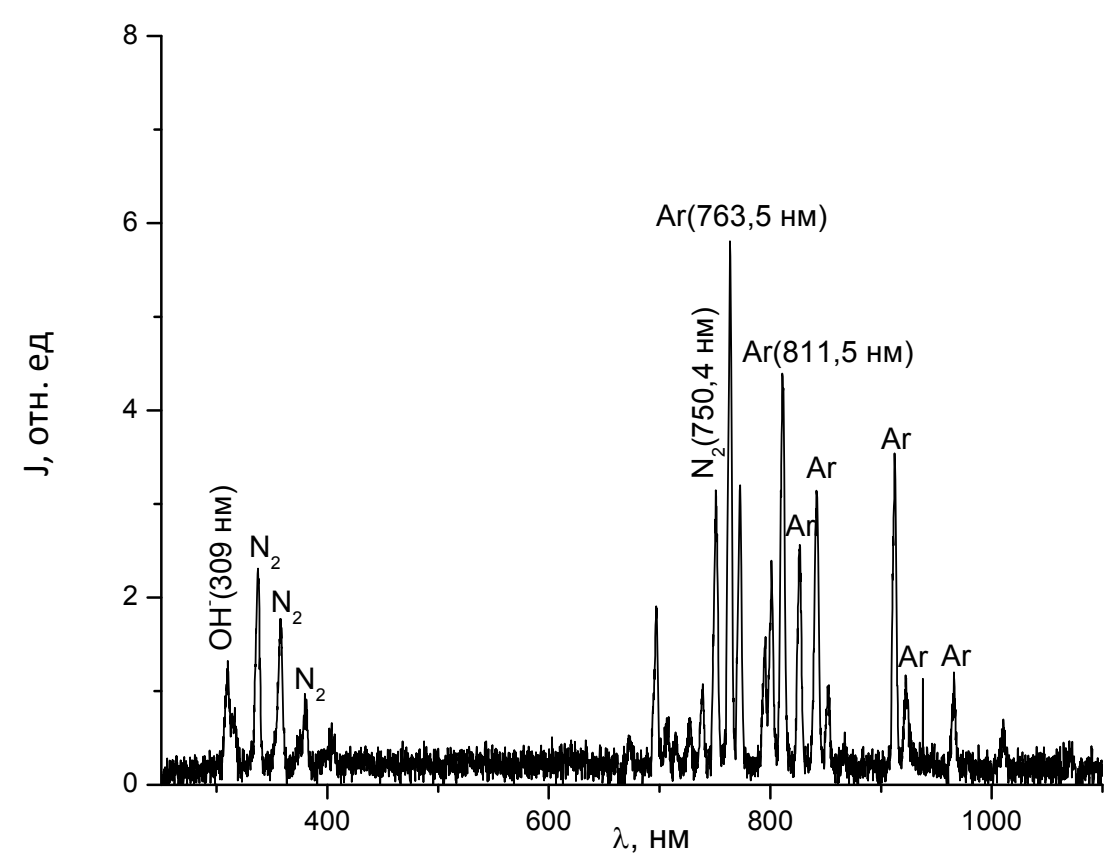

Рис. 6. Спектральное распределение интенсивности излучения, снятое поперек движения факела на расстоянии от сопла 2 мм. Поток аргона 0,32 л/мин

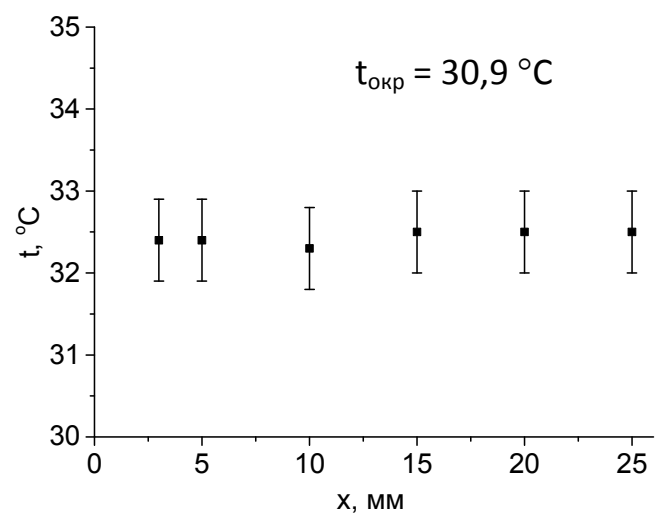

Рис. 7. Температура плазменного факела в различных участках вдоль направления течения газа. Скорость потока аргона 0,32 л/мин

\section{3. Исследование воздействия плазменной струи на основе барьерного разряда наносекундной длительности в смеси аргона и воздуха атмосферного давления на биологическую ткань}

В работе проводились микрофлуоресцентные исследования воздействия низкотемпературной плазменной струи на биоткань на образцах нормальной ткани печени in vitro. Выбор данной ткани обусловлен тем, что она имеет однородную структуру и предполагаемые изменения после обработки плазмой на ней могут быть наиболее выражены. Данные образцы представляли собой кусочки средним размером $10 \times 10 \times 5,0$ мм. Для микроскопического исследования этих образцов перед процедурой плазменного воздействия были сделаны срезы толщиной 15 и 30 мкм при помощи криостатного микротома CM-1510 S (Leica Microsystem, Германия). Сами срезы фиксировались на кварцевых стеклах. Таким образом, плазменному воздействию подвергались уже непо- 
Ашурбеков Н.А., Шахсинов Г.Ш., Исрапов Э.Х., Исаева З.М. Взаимодействие низкотемпературной плазменной струи атмосферного давления в смеси воздуха и аргона с биотканями

средственно полученные срезы. Затем каждый срез условно делился на две половины, одна из которых подвергалась воздействию плазмы, а другая использовалась для сравнения. В итоге для каждого среза формировались две области: облученная и необлученная.
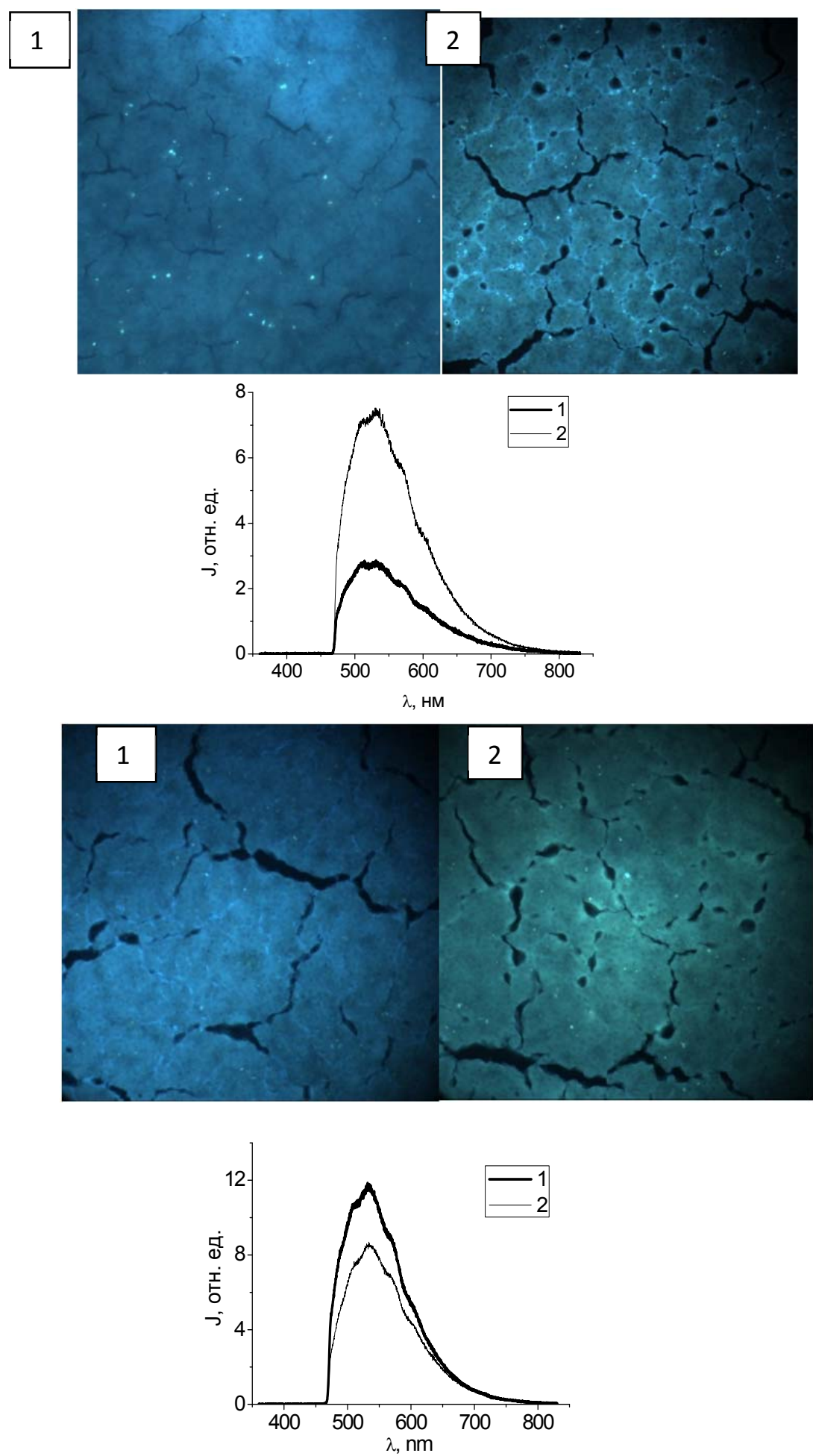

Рис. 7. Фотографии поверхности биологической ткани толщиной 15 мкм (первый ряд) и 30 мкм (второй ряд) под $\times 400$ увеличением микроскопа и спектр флуоресценции ( 1 - до облучения плазменным факелом, 2 - после облучения) 
Зондирование образцов плазменным факелом проводилось в течение 5 минут, при этом образцы располагались перпендикулярно факелу на расстоянии до 1,5 см от торца плазменного волновода. Поток газа был зафиксирован на значении в 0,32 л/мин, при котором плазменный факел достигал наибольшей длины.

Практически сразу после облучения на срезы биотканей наносилась специальная монтирующая жидкость Immu-Mount (Thermo Scientific, США) для выравнивания коэффициента преломления, а поверх нее укладывались специальные предметные стекла для микроскопии.

Исследование микрофлуоресцентных свойств биоткани до и после облучения проводились на базе люминесцентного микроскопа Eclipse Ni-U (Nikon, Япония).

Возбуждение флуоресценции осуществлялось ртутной лампой на длине волны 365 нм. Свет флуоресценции собирался объективом микроскопа и, пройдя систему запирающих светофильтров с полосой пропускания 400-700 нм, направлялся в фокальную плоскость визуального окуляра, либо фотоокуляром в плоскость матрицы $C C D$ камеры. В данных исследованиях применялся объектив с Nicon S Fluor $\times 40 / 0.50$ при общем увеличении микроскопа до $\times 400$ раз.

Данный микроскоп имел выход и на монохроматор-спектрограф MS3504I (SOL Instruments, Минск), который позволил нам снять спектры флуоресценции с исследуемых точек на поверхности срезов.

Результаты данного микроскопического исследования приведены на рисунке 7. Проведенные экспериментальные исследования показывают, что эффект воздействия низкотемпературной плазменной струи на спектр флуоресценции биоткани является существенным, однако зависит от толщины образца. По-видимому, это связано с тем, что глубина воздействия активных частиц плазмы (азот- и кислородсодержащих радикалов, ионов и других активных частиц) значительно меньше, чем глубина проникновения в биоткань зондирующего оптического излучения, поэтому спектры флуоресценции получаются усредненные по глубине образца и зависят от толщины образца биоткани.

Конкретные механизмы воздействия низкотемпературной плазмы на спектры флуоресценции требуют дополнительных исследований и анализа наблюдаемых закономерностей.

В заключение отметим, что разработанная и исследованная в данной работе газоразрядная система формирования струи низкотемпературной плазмы на основе барьерного импульсного разряда в потоке смеси газов аргон-воздух обеспечивает формирование УФ излучения, ионов, кислород- и азотсодержащих радикалов, необходимых для эффективного воздействия на биообъект при комнатных температурах. Показано, что путем изменения расхода газа можно формировать плазменную струю, состоящую из нескольких компонент, и тем самым регулировать плотность плазмы.

Работа выполнялась с использованием оборудования центра коллективного пользования Дагестанского государственного университета «Аналитическая спектроскопия».

\section{Литература}

1. Sysolyatina E., Vasiliev M., Kurnaeva M., Kornienko I., Petrov O., Fortov V., Ermolaeva $S$. Frequency of cell treatment with cold microwave argon plasma is important for the 
final outcome // Journal of Physics D: Applied Physics. - 2016. - № 49 (29). - P. 294002. doi:10.1088/0022-3727/49/29/294002

2. Babaeva N.Y., Naidis G.V. Modeling of plasmas for biomedicine // Trends in biotechnology. - 2018. - № 36 (6). - P. 603-614.

3. Staak D., Farouk B., Gutsol A., Fridman A. Characterization of a dc atmospheric pressure normal glow discharge // Plasma Sources Sci. Technol. - 2005. - V. 14, № 4. P. 700-711.

4. Neyts E.C. et al. Computer simulations of plasma-biomolecule and plasma-tissue interactions for a better insight in plasma medicine // J. Phys. D: Appl. Phys. - 2014. - V. 47, № 14. - P. 293001.

5. Nosenko T., Shimizu T., Morfill G. Designing plasmas for chronic wound disinfection // New Journal of Physics. - 2009. - V. 11, № 11. - P. 115013

6. Morfill G.E., Kong M.G., Zimmermann J.L. Focus on Plasma Medicine // New Journal of Physics. - 2009. - V. 11, № 11. - P. 115011.

7. Neyts E.C., Yusupov M., Verlackt C.C., Bogaerts A. Computer simulations of plasma-biomolecule and plasma-tissue interactions for a better insight in plasma medicine // J. Phys. D: Appl. Phys. - 2014. - V. 47, № 29. - P. 293001.

8. Nie Q., Cao Z., Ren C.S., Wang D.Z., Kong M.G. A two-dimensional cold atmospheric plasma jet array for uniform treatment of large-area surfaces for plasma medicine // New Journal of Physics. - 2009. - V. 11, № 11. - P. 115015.

9. Kong M.G., Kroesen G., Morfill G., Nosenko T., Shimizu T., van Dijk J. et al. Plasma medicine: an introductory review // New Journal of Physics. - 2009. - V. 11, № 11. P. 115012.

10. Yan D., Nourmohammadi N., Talbot A., Sherman J.H., Keidar M. The strong antiglioblastoma capacity of the plasma-stimulated lysine-rich medium // Phys. D: Appl. Phys. 2016. - V. 49, № 27. - P. 274001.

11. Dolci L.S., Liguori A., Merlettini A., Calzà L., Castellucci M., Gherardi M. et al. Antibody immobilization on poly(L-lactic acid) nanofibers advantageously carried out by means of a non-equilibrium atmospheric plasma process // J. Phys. D: Appl. Phys. - 2016. V. 49, № 27. - P. 274003.

12. Oh J.-S., Szili E.J., Gaur N., Hong S-H., Furuta H., Kurita H. et al. How to assess the plasma delivery of RONS into tissue fluid and tissue // J. Phys. D: Appl. Phys. - 2016. V. 49, № 30. - P. 304005.

13. Kartaschew K., Baldus S., Mischo M., Bründermann E., Awakowicz P., Havenith $M$. Cold atmospheric-pressure plasma and bacteria: understanding the mode of action using vibrational microspectroscopy // J. Phys. D: Appl. Phys. - 2016. - V. 49, № 37. - P. 374003.

14. Aboubakr H.A., Gangal U., Youssef M.M., Goyal S.M., Bruggeman P.J. Inactivation of virus in solution by cold atmospheric pressure plasma: identification of chemical inactivation pathways // J. Phys. D: Appl. Phys. - 2016. - V. 49, № 20. - P. 204001.

15. Boekema B.K.H.L., Vlig M., Guijt D., Hijnen K., Hofmann S., Smits P. et al. A new flexible DBD device for treating infected wounds: in vitro and ex vivo evaluation and comparison with a RF argon plasma jet // J. Phys. D: Appl. Phys. - 2015. - V. 49, № 4. P. 044001. 
Ашурбеков Н.А., Шахсинов Г.Ш., Исрапов Э.Х., Исаева З.М. Взаимодействие низкотемпературной плазменной струи атмосферного давления в смеси воздуха и аргона с биотканями

16. Bogaerts A., Khosravian N., Van der Paal J., Verlackt C.C.W., Yusupov M., Kamaraj B. et al. Multi-level molecular modelling for plasma medicine // J. Phys. D: Appl. Phys. 2015. - V. 49, № 5. - P. 054002.

17. Ishaq M., Bazaka K., Ostrikov K. Pro-apoptotic NOXA is implicated in atmospheric-pressure plasma-induced melanoma cell death // J. Phys. D: Appl. Phys. - 2015. - V. 48, № 46. - P. 464002 .

18. Kaushik N.K., Kaushik N., Min B., Choi K.H., Hong Y.J., Miller V., et al. Cytotoxic macrophage-released tumour necrosis factor-alpha (TNF - $\alpha$ ) as a killing mechanism for cancer cell death after cold plasma activation // J. Phys. D: Appl. Phys. - 2016. - V. 49, № 8. P. 084001.

19. Kelly S., Golda J., Turner M.M., Schulz-von der Gathen V. Gas and heat dynamics of a micro-scaled atmospheric pressure plasma reference jet // J. Phys. D: Appl. Phys. - 2015. - V. 48, № 44. - P. 444002.

20. Katz J., Gershman S., Belkind A. Optical Emission Spectroscopy and Contact Angle Study of Plasma Cleaning of Titanium Alloy Surfaces: Argon Plasma // Plasma Medicine. - 2015. - V. 5, № 2-4. - P. 223-236.

21. Song K., Li G., Ma Y. A Review on the Selective Apoptotic Effect of Nonthermal Atmospheric-Pressure Plasma on Cancer Cells // Plasma Medicine. - 2014. - V. 4, № 1-4. P. 193-209.

22. Lu X., Naidis G.V., Laroussi M., Ostrikov K. Guided ionization waves: Theory and experiments // Physics Repots. - 2014. - V. 540, № 3. - P. 123-166.

23. Ашурбеков Н.А., Курбанисмаилов В.С., Омаров О.А., Омарова Н.О. Кинетика возбужденных атомов и оптического излучения при волновом пробое инертных газов // Теплофизика высоких температур. - 2000. - Т. 38, № 5. - С. 823.

24. Ашурбеков Н.А., Борисов В.Б., Егоров В.С., Кардашов В.Р. Оптимизация параметров возбуждения плазменного лазера в смеси неон-водород продольным наносекундным разрядом.// Оптика и спектроскопия. - 1995. - Т. 78, № 6. - С. 999.

25. Ашурбеков Н.А., Иминов К.О. Усиление света на $3^{3} \mathrm{D}-2^{3} \mathrm{P}$ переходе атома гелия в разряде в смеси гелий-аргон // Оптика и спектроскопия. - 1990. - Т. 68. № 1. - С. $48-51$.

26. Chen C., Liu D.X., Liu Z.C., Yang A.J., Chen H.L., Shama G., Kong M.G. A Model of Plasma-Biofilm and Plasma-Tissue Interactions at Ampient Pressure // Plasma Chem Plasma Process. - 2014. - V. 34. - P. 403-441.

27. Begum A. (2010). Experimental investigation of a non-thermal atmospheric pressure plasma jet (Order № 3429591). Available from ProQuest Dissertations \& Theses Global. (759504885).

Поступила в редакиฺию 18 апреля 2019 г. 
UDC 537.523

DOI: $10.21779 / 2542-0321-2019-34-2-19-35$

\title{
The Interaction of Low-Temperature Plasma Jet of Atmospheric Pressure with Biotissues in a Mixture of Air and Argon
}

\author{
N.A. Ashurbekov ${ }^{1}$, G.Sh. Shakhsinov ${ }^{1}$, Ed.Kh. Israpov ${ }^{1,2}$, Z.M. Isaeva ${ }^{1}$ \\ ${ }^{1}$ Dagestan State University; Russia, 367001, Makhachkala, M. Gadzhiev st., 43a; nash- \\ urb@mail.ru \\ ${ }^{2}$ Amirkhanov Institute of Physics, Dagestan Scientific Center, Russian Academy of Sci- \\ ences; Russia, 367003, Makhachkala, M. Yaragskiys., 94; ed-gar1993@yandex.ru
}

The system of gas-discharge used for the formation of a low-temperature plasma jet in an airargon mixture for biomedical applications has been developed and investigated. The design of the plasma source is described and the experimental results of the study of the spatial structure of the plasma jet, the spectral composition of the irradiation and the temperature in different parts of the plasma jet are presented. Preliminary microfluorescent studies of the effects of low-temperature plasma jets on in vitro liver tissue samples have been performed.

Keywords: plasma medicine, plasma jet, nanosecond barrier discharge.

Received 18 April, 2019 